\title{
The role of different types of skills and signals in youth labor market integration
}

\author{
Ardita Muja* ${ }^{*}$, Lieselotte Blommaert, Maurice Gesthuizen and Maarten H. J. Wolbers
}

${ }^{*}$ Correspondence:

a.muja@maw.ru.nl

Department of Sociology,

Radboud University, P.O.

Box 9104, 6500 HE Nijmegen,

The Netherlands

\begin{abstract}
This paper investigates to what extent self-rated job-specific and generic skills and different types of educational signals are positively related to the labor market integration process of Dutch graduates, 18 months after finishing upper secondary vocational education. Our contributions to the current literature are that of simultaneously investigating these different types of skills and (a more extensive concept of) educational signals, and moreover examining to what extent the impact of self-rated specific skills and educational signals differ between the four labor market outcomes under investigation. We analyzed secondary survey data from the VET survey collected in the Netherlands in 2015. Results indicate that (1) self-rated specific skills-acquired either in education or on the job-are more positively related to favorable labor market outcomes than self-rated generic skills in the first 18 months of graduates' integration process, (2) only certain educational signals positively impact labor market integration, and (3) the positive impact of self-rated specific skills and signals varies between different labor market outcomes.
\end{abstract}

Keywords: School-to-work transitions, Youth labor market integration, Vocational education, Self-rated job-specific skills, Signals, Graduated school-leavers, The Netherlands

\section{Introduction}

The transition from school to work is regarded as a precarious period for young people, as they often have to deal with periods of job searching, occupational mismatches and flexible contracts (Levels et al. 2014; Scherer 2005; Wolbers 2003). Education plays a decisive role in preparing youth for the labor market, and the provision of skills and qualifications is therefore one of the key tasks of the education system (Van de Werfhorst 2014). This 'labor market task' is most strongly featured in vocational education, by providing students with skills that make them productive for work, which ultimately optimizes their labor market perspectives (Van de Werfhorst and Mijs 2010). As time within a curriculum is limited and a trade-off likely occurs in time spent on acquiring one skill at the expense of the other (e.g. Meng 2006), it is important to consider which types of skills play a more positive role in graduated school-leavers' labor market integration.

Additionally, in the absence of a readily assessable level of skills, educational signals (Spence 1973) can be complementary means for employers to assess information about

(C) The Author(s) 2019. This article is distributed under the terms of the Creative Commons Attribution 4.0 International License (http://creativecommons.org/licenses/by/4.0/), which permits unrestricted use, distribution, and reproduction in any medium, provided you give appropriate credit to the original author(s) and the source, provide a link to the Creative Commons license, and indicate if changes were made. 
graduates' level of productivity, which, if positive, optimizes graduates' labor market perspectives (Bills 2003; Iannelli and Raffe 2007). Thus, vocational education provides students with different types of skills and signals, both of which are important resources for young people to enter the labor market (Hannan et al. 1997).

In this paper, we contribute to this discussion by investigating both the role of different types of self-evaluated skills and signals in graduates' labor market integration process, one and a half year after finishing vocational education in the Netherlands. As the graduates under investigation reflect on their integration process after 18 months from graduation, we largely but not solely capture the self-rated skills acquired in education, as these self-perceived skills may have further accumulated on the job and over time. Hence, we examine the impact of signals on labor market integration, but in the case of self-rated skills, we only examine their relationship with certain labor market outcomes. Our first research question reads as follows: To what extent are self-rated specific and generic skills and different types of educational signals positively related to the labor market integration process of graduated school-leavers from vocational education in the Netherlands?

Besides the evident societal relevance for the Netherlands, the findings of this study are also important for other countries, as they lend relevance to the overall question to what extent different types of skills and educational signals are beneficial for youth's labor market integration. Moreover, we want to stress why the Netherlands is an ideal test case for the very purpose of our study. The Dutch upper secondary Vocational Education and Training system (VET; MBO in Dutch) entails variation in vocational specificity both in educational level (four levels with increasing cognitive difficulty) and, within each level, variation in type of track (work-based versus school-based learning track). These variations in vocational specificity within the Dutch VET system provide interesting opportunities to study the role of skills and educational signals among a very comparable group of VET graduates.

Our paper builds upon insights from existing research by addressing several unanswered questions. First, most previous empirical studies lack measures of job-specific skills on the individual level, because there simply is no such data available (see also Dieckhoff 2008; Heisig and Solga 2015; Protsch and Solga 2015). Barone and Van de Werfhorst (2011) measure specific cognitive skills in their study, but state that their "focus on work-specific cognitive abilities does not pay full tribute to the skills that are rewarded for reasons explained by human capital theory" (p. 488). Furthermore, we found one study that uses the same measures of self-rated specific and generic skills, examining only higher educated graduates (Heijke et al. 2003). On the contrary, the measurements of generic skills are quite advanced and well-studied (Bol and van de Werfhorst 2013; Heisig and Solga 2015; Pfeffer 2015), because of existing accurate measurements that are available in international data collection projects such as the International Adult Literacy Survey (IALS) and the Programme for the International Assessment of Adult Competencies (PIAAC), both conducted by the OECD.

This study has measurements of both specific and generic skills, obtained through self-assessed ratings of VET graduates' level of skills one and a half years after graduation. We are well aware of biases that can occur due to self-assessments 18 months after graduating. However, to our knowledge, we are finally able to include a measurement of 
specific skills (on the micro-level) compared to previous studies, by which we provide a, perhaps not perfect, step forward, and by which we aim to provide new insights on the relation between self-rated specific skills and youth labor market integration.

Second, we argue, among others, that education does not necessarily consist of only one signal in the form of a degree (e.g. Andersen and Van de Werfhorst 2010; Protsch and Solga 2015). Our next contribution is thus the use of a more extensive concept of educational signals by investigating different types of signals and separately theorize why and how each signal affects the labor market integration process. Some of these signals have and others have not yet been investigated. In this paper, the signals under investigation are: having attended an internship at the firm (only investigated for the IT-sector among other educational groups in vignette study, Di Stasio and Van de Werfhorst 2016), the educational level within the VET system (cross-nationally on macro-level, e.g. Heisig and Solga 2015), the average graduation grade (e.g. Protsch and Solga 2015), and the choice of a school-based versus work-based tracks (cross-nationally on macro-level, e.g. Andersen and Van de Werfhorst 2010).

Finally, our third contribution is that we examine whether the impact of self-rated skills and signals differ between various indicators of labor market integration, and if so, for which of the labor market outcomes the impact is stronger. Although a majority of school-to-work transition studies examines multiple indicators of labor market integration (e.g. Coenen et al. 2015; De Grip and Wolbers 2006; Levels et al. 2014; Vogtenhuber 2014; Wolbers 2007), they do not a priori theorize nor empirically test whether and why skills and signals have a stronger impact for one outcome compared to the other. Consequently, this question has remained under-investigated to our knowledge. As such, this study examines differences between the following indicators of labor market integration: immediate job entry (after graduation), horizontal job matching (i.e. a match with field of education), vertical job matching (i.e. a match with level of education), and job security (having a permanent employment contract). All in all, the second question this paper addresses is: To what extent does the role of self-rated specific skills and the role of signals vary between different labor market outcomes among graduated school-leavers from vocational education in the Netherlands?

\section{Description of the Dutch education system}

To provide a better understanding of the manifestation of the micro-level explanations in the next section, it is necessary to increase understandings of the Dutch education system, as the transition takes place within this context. The first way in which this can be done is to compare (features of) the Dutch system with other national education systems. The Dutch education system is highly stratified (degree of tracking), standardized (degree of nationwide comparability of educational curricula, exit examinations etc.), and vocationally specific with strong linkages between education and the labor market (i.e. frequent contact and updating; involvement of employers in the curricular design of educational programmes) (e.g. Kerckhoff 2001). Based on these institutional features, the Dutch system is often compared to and clustered with German-speaking countries, such as Germany, Switzerland, and Austria (Iannelli and Raffe 2007; Raffe 2008; Van der Velden and Wolbers 2007). In these countries, all characterized by dual or 
apprenticeship systems, graduated school-leavers experience a smoother transition from school to employment compared to their counterparts from less vocationally oriented education systems (Iannelli and Raffe 2007; Raffe 2008; Scherer 2005; Wolbers 2007).

The second way to increase understandings of the Dutch education system is to explain the structure of education in the Netherlands. Tracking occurs after primary school when pupils enter secondary education at the age of 12 in which they are allocated to three major tracks. In order of increasing cognitive or academic difficulty, pupils can enter either: (1) pre-vocational education (VMBO in Dutch), which gives access to VET (MBO in Dutch); (2) senior general secondary education (HAVO), which gives pupils access to tertiary, non-academic education (HBO); or (3) pre-university education (VWO), which gives access to universities (WO).

Of all the educational trajectories, VET (or MBO) is the most occupationally specific and most strongly linked to the labor market and organized in close collaboration with its social partners (Di Stasio and Van de Werfhorst 2016; Ministry of Education Culture and Science 2016). When zooming in on the Dutch VET context, students are sorted into four educational levels that differ in cognitive difficulty and admission requirements based on prior educational achievements. With each increasing level, the duration of a (full-time) programme also increases, ranging from 1 to 4 years. The lowest VET level prepares students for assistant positions in the labor market, whereas the highest level includes middle-management programmes, which prepare students for a coordinating and managing occupational position. For example, a lead artisan baker (middle-management position) carries out activities for the preparation of bakery products, but is moreover responsible for the execution of the activities in the bakery.

Next, within each VET level, students can choose a vocational programme in their field of interest and whether they want to follow this programme via a school-based learning route in which at least $20 \%$ but typically around $30 \%$ takes place in the workplace (BOL in Dutch), or a work-based route in which work and study are combined and at least $60 \%$ of learning takes place in the workplace (BBL in Dutch). In a nutshell, the biggest difference between the two type of tracks is whether students are predominantly trained within the context of the school or firm. The school-based track is a combination of school and internships where students spend most of the time at school. Students in a work-based track or 'apprenticeship pathway' are apprentices at firms and go to school once or twice a week.

\section{Theoretical background}

\section{Skills}

We start off by addressing the question of which type of skill acquired in school and in the labor market by VET graduates is more positively related to labor market integration. From a human capital perspective (Becker 1964), the general assumption is thatregardless of the type of skills - the more skills individuals acquire in education (general human capital) and within a firm (occupation-specific human capital), the higher their labor productivity, which, in turn, increases their labor market returns. While we agree that all types of skills do increase labor market productivity, we argue that the extent to which this occurs can actually vary between specific and generic skills, depending on the VET system and labor market context (Iannelli and Raffe 2007; Shavit and Müller 1998). 
So, in order to further theorize which type of skills is more positively related to labor market integration, we first have to take into account the Dutch VET and labor market context. Within the Dutch context of VET with its strong focus on and strong linkage with the labor market (Hannan et al. 1997; Iannelli and Raffe 2007), it can be assumed that when VET students have more specific skills, they are better prepared and more immediately productive on the job (market) compared to when having more generic skills (Hanushek et al. 2017). Theoretically, this suggest that when VET graduates have more specific skills rather than more generic skills, they are more likely to experience immediate job entry (Wolbers 2007), find a job that matches their skills (Levels et al. 2014), and find permanent employment (Scherer 2005).

Furthermore, graduates' acquisition of job-specific skills does not stop in education, but can be further accumulated in jobs, which is in accordance with occupation-specific human capital theory (Becker 1964). These acquired skills are, to some extent, transferrable to other firms as well (e.g. Lazear 2009). Thus, whether graduates have acquired job-specific skills in school or within a firm, the more job-specific skills they have accumulated over time, the more prosperous their labor market returns. Based upon these arguments, our first hypothesis reads:

Among VET graduates, having more self-rated specific skills is more positively related to immediate job entry (H1a), horizontal matching (H1b), vertical matching (H1c) and job security (H1d) than having more self-rated generic skills.

\section{Signals}

Next to the role of skills, we address the question regarding the relation between graduates' educational signals and labor market integration. In contrast with graduates' acquisition of skills in both education and the labor market, educational signals are obtained in education. Spence (1973) argues that employers have little information about the actual level of job seekers' productive skills and use educational degrees instead as a 'signal' that contains information about one's potential productivity, ability, and trainability (Arum and Shavit 1995). Moreover, these degrees represent other unobserved qualities of job seekers, such as commitment, perseverance, and motivation (Arrow 1973; Bol and Van de Werfhorst 2011).

What is then the use of signaling for employers concretely? When job seekers' actual level of skills is imperfect, limited, or not at all observable for others, the use of signals is very valuable as complementary means for employers, as they send additional information about job seekers' productive capacity (Bills 2003), which can, if the signals are positive and clear, optimize their labor market perspectives. This suggests that graduates' educational signals can have a relationship with labor market integration independently and complementary of the relationship with graduates' actual skills.

However, the strength, clarity, and positivity of vocational educational signals, once again, depend on the educational and labor market context (Meng 2006; Vogtenhuber 2014). As mentioned earlier, the Dutch VET context has a strong focus on and linkage with the labor market. Previous research has found that in countries with strong linkages between education and the labor market, strong and clear signals are sent between the two contexts (Hannan et al. 1997; Iannelli and Raffe 2007; Raffe 2008; Vogtenhuber 
2014). Moreover, the stronger this linkage, the more positive is the impact of vocational signals on labor market outcomes for VET graduates (Iannelli and Raffe 2007). Based upon this, we argue that positive, strong, and clear signals can be sent between the VET system and the labor market within the Dutch context.

The question remains to what extent the four educational signals (internship at the firm, type of track, VET level, and graduation grade) under investigation are positively related to labor market integration among VET graduates. In other words, when, why and how does each educational signal send a more positive signal?

The first educational signal under investigation is having completed an apprenticeship, which is a regular feature in Dutch VET programmes. According to network theories (Rosenbaum et al. 1990), one of the reasons why vocational education has a positive impact on labor market integration, is because vocational programmes give students access to possible future employers and/or their networks (Iannelli and Raffe 2007). This access can be available through a strong linkage between VET programmes and the labor market, resulting in a closer involvement of employers, which can facilitate closure via networks (Di Stasio and Van de Werfhorst 2016; Iannelli and Raffe 2007; Rosenbaum et al. 1990). This access can additionally be established through apprenticeship training or a prior (paid) job, which provides employers direct information about students' level of productivity or trainability, but also otherwise more difficult to observe qualities, such as commitment, perseverance, and motivation. Di Stasio and Van de Werfhorst (2016) state that "following the closure by networks argument, employers should favor applicants with a pre-existing relation with the firm to compensate for poor education signaling" (p. 84). They argue that this would especially be the case in weakly stratified and more generalist education systems. Although we do not disagree with the authors' line of reasoning within their framework, we do still expect a positive impact of a pre-existing relationship with a firm through an apprenticeship (or a paid job) as it simply provides first-hand, direct information about one's productivity and (train)ability-even if the educational signaling is quite clear in the Netherlands.

All in all, we argue that a positive pre-existing relationship with a firm through an apprenticeship or a prior (paid) job can strongly increase graduates' chances of getting a job in that same firm after graduation (Di Stasio and Van de Werfhorst 2016; Levels et al. 2014). This positive impact seems very common in countries with a dual apprenticeship system or a work-based VET system, since many apprentices stay with their firm as an employee after completing their apprenticeship (Protsch 2017). Hence, our second hypothesis reads as follows:

Among VET graduates, a pre-existing relationship with a firm through an internship or a (paid) job is more positively related to immediate job entry (H2a), horizontal matching (H2b), vertical matching (H2c) and job security (H2d) than not having a pre-existing relation with a firm.

Second, in most cases, Dutch VET students can follow either a work-based track (at least $60 \%$ of learning takes place in the workplace) or a school-based track (typically around 30\% takes place in the workplace) of their programme. Because of its clearer and stronger vocational specificity, we argue that graduates who completed a work-based track signal more on-the-job experience, which, as a consequence, also signals that these 
graduates are better prepared and more immediately productive on the job than graduates from a school-based track. Our third hypothesis therefore reads:

Among VET graduates, finishing a work-based track is more positively related to immediate job entry (H3a), horizontal matching (H3b), vertical matching $(H 3 c)$ and job security (H3d) than finishing a school-based track.

Third, the Dutch VET system consists of four levels with increasing (cognitive) difficulty. Based on signaling theory, one's productivity, ability, and trainability is judged based on signals of educational attainment (Spence 1973). The lower one's educational attainment or degree is, the lower the rank in the labor queue will be (Gesthuizen et al. 2010). We therefore expect that students with a higher VET level send a more positive signal to employers compared to students with a lower VET level. This suggests the following hypothesis:

Among VET graduates, finishing higher levels of education within VET is more positively related to immediate job entry (H4a), horizontal matching (H4b), vertical matching (H4c) and job security (H4c) than finishing lower levels of education within VET.

Finally, signaling and queuing approaches stress the importance of grades as cheap and easy-to-observe signals of cognitive ability or trainability (see also Di Stasio and Van de Werfhorst 2016; Protsch 2017; Protsch and Solga 2015). Similar to these previous studies, we examine average graduation grade. For employers, higher grades signal perseverance, and trainability potential, and are indirectly related to productivity (Di Stasio and Van de Werfhorst 2016; Protsch and Solga 2015; Weiss 1995). These signals are attractive for employers, as they benefit most from employees who are productive and require little training, saving additional training costs (Thurow 1976). We thus predict that the higher graduates' average graduation grade is, the more positive the signal is to employers, as it indicates an overall higher level of ability, trainability, motivation, and perseverance (Protsch and Solga 2015). This leads to the next hypothesis:

Among VET graduates, obtaining higher average graduation grades is more positively related to immediate job entry (H5a), horizontal matching (H5b), vertical matching (H5c) and job security (H5d) than obtaining lower average graduation grades.

\section{Differences between labor market outcomes}

Theoretically and empirically, it remains unclear to what extent the impact of signals and skills may be different between various indicators of labor market integration. In other words, it remains unclear whether and why signals and skills have a stronger impact for one outcome compared to the other.

Educational signals have proven to be a very important means for employers to screen applicants, especially when dealing with job seekers who are trying to enter the labor market for the first time. As information about applicants' real productivity is imperfect during the first stages of hiring processes, employers often resort to educational signals, which are available before hiring, as an indication of applicants' productivity or 
trainability (Protsch and Solga 2015; Spence 1973; Thurow 1976). Hence, graduates may have greater chances in experiencing immediate entry by means of their educational signals compared to job matching and job security, because the latter outcomes are accompanied by greater risks of additional costs which employers can prevent by not taking these decisions based on incomplete information about one's productivity (i.e. educational signals). This leads to the following hypothesis:

For VET graduates, educational signals are more positively related to immediate job entry, compared to horizontal matching (H6a), vertical matching (H6b) and job security (H6c).

Next, we expect graduates' job-specific skills to be relatively more important when it comes to having a matching job and obtaining permanent employment compared to immediate entry. The allocation of applicants to a matching or permanent job is a risky hiring decision for employers to make under imperfect information conditions, because it is accompanied by either additional training costs (in order to match one's skills to the job) or higher firing costs regarding permanent contracts compared to temporary contracts (Scherer 2005; Levels et al. 2014; Noelke 2015). These risks can be reduced by relying on more direct information about applicants' productivity: their actual skills. Against this background, we argue that graduates' specific skills are more positively related to these outcomes compared to immediate entry into the labor market, assuming that first entry jobs are allocated on the basis of signals and entail minimal risks for employers. This suggests our final hypothesis:

For VET graduates, self-rated specific skills are more positively related to horizontal matching (H7a) vertical matching (H7b) and job security (H7c) than to immediate job entry.

\section{Data and measurements}

To test our hypotheses, we use data from the 2015 VET survey carried out by the Research Centre for Education and the Labor Market (ROA) of Maastricht University. This annual survey is designed to analyze the transition of graduated school-leavers from VET to continuous education or the labor market. For this purpose, school-leavers are questioned one and a half year after their graduation by means of either the written or online version of the questionnaire. The survey collects information about graduates' educational career in retrospect, and their current educational and labor market activities.

Given the focus on VET graduates' first entry into the labor market, we had to select respondents on a number of criteria to capture their initial school-to-work transition. The most important and inevitable selection is that graduates had to have a paid job at the time of the survey, as only these respondents had to answer (further) questions about their labor market outcomes. All in all, we selected VET graduates who at the time of the survey (i) are aged between 18 and 27, (ii) do no longer study, (iii) have not obtained another (higher) degree within one and a half year, (iv) have a paid job, and (v) are not self-employed or working freelance. Furthermore, according to the widely used International Standard Classification of Education (ISCED), (upper secondary) VET is equal to 
ISCED 3. We therefore restricted our analyses solely to respondents from VET levels 2, 3 and 4, because the other VET levels 1 and $4+$ (specialist training) are equal to respectively ISCED 2 and ISCED 4 . The data sample relevant for our study ultimately consisted out of 8257 respondents.

\section{Labor market outcomes}

Immediate job entry was measured with the question: "Have you been unemployed after you finished the VET programme?". A majority of the respondents $(81.1 \%)$ indicated to have experienced no unemployment after their programme, which meant that they experienced immediate job entry (1) as opposed to a delayed entry (0). This skewed distribution was also found in the original data sample $(82.7 \%$ experienced immediate entry) before any selections were implemented.

Horizontal job matching indicates whether (1) or not (0) respondents have a current job for which their employer(s) had asked for a matching (or a related) field of study. Vertical job matching indicates whether (1) or not (0) graduates have a current job for which their employer(s) had asked a matching level of education.

Finally, job security indicates whether graduates have a permanent employment contract (1) versus a temporary or zero-hour contract (0). Job security was measured with the question: 'Type of contract', consisting of three response categories, namely 'permanent employment' (1), 'temporary employment' (0), and 'not applicable'. Respondents who had a missing or answered 'not applicable', but did answer the question 'Type of employment' with 'zero-hour contract', were included and coded as dealing with job insecurity.

After we excluded missing values for the dependent variables (16.0\%) through listwise deletion, the sample was reduced to 6938 respondents. Although this seems like a high percentage of respondents with missing values to simply exclude from the sample, within this group of respondents around half of them (48.7\%) had not answered more than $60 \%$ of the questions that all respondents were asked in the survey. If we would disregard this group, a total of $8.9 \%$ of the missing on the dependent variables would be found among respondents that actually had valid answers on the majority of the survey.

\section{Specific and generic skills}

The explanatory variable specific skills ${ }^{1}$ was measured using a self-reporting approach in which respondents were asked to indicate their own level of skills on a 5-point Likert scale, ranging from mediocre to excellent. Based on the literature, the items related to specific skills were 'vocational knowledge' and 'the ability to apply vocational knowledge and techniques in practice' (Van der Velden 2011). The average score of these two items was taken to construct a measure of specific skills (Cronbach's alpha of 0.64). This may

\footnotetext{
${ }^{1}$ Comparisons between self-rated skills and objective indicators of vocational specificity provide us more insights into the validity of graduates' self-perceived level of skills. Present in our data we have information about graduates' attended VET track and whether they completed an apprenticeship at the firm they are currently working. We consider these two measures to be objective indicators of vocational specificity as they have influenced graduates' time spent on acquiring vocationally specific competencies (at the firm they are currently working). Results from bivariate correlations and multivariate linear regression models accounting for all (other) variables included in this study seem to indicate that these objective indicators of vocational specificity are slightly stronger related to higher self-perceived specific skills than selfperceived generic skills among graduates (results available upon request).
} 
not seem as a very high degree of reliability, but it is important to keep in mind that the reliability test is also affected by the number of items included. Generally, more items lead to a higher degree of reliability. To take this into account, we calculated the Spearman-Brown prophecy formula in order to predict the reliability of the test after changing the test length (number of items). If we had the double amount of items, in this case four instead of two items, the Cronbach's alpha would be 0.77 , which is reasonably high.

In addition, generic skills were measured with the same self-reporting approach. In accordance with previous literature, the following three items have been used to measure basic generic skills: written, oral, and numeracy skills (Meng 2006; Van der Velden 2011). These three components of generic skills are internationally examined as such, by means of widely used assessments, such as the IALS and PIAAC, both conducted by the OECD. The average score of these items was calculated to have one overall measure of generic skills (Cronbach's alpha of 0.61). Again, we calculated the Spearman-Brown formula and doubled the number of items to six, which led to a Cronbach's alpha of 0.75 . In case of both types of skills, a higher score indicates a higher self-reported level of specific or generic skills. A positive correlation was found between the scaled specific and generic skills (Pearson's $r=0.412, \mathrm{p}<0.001$ ). Respondents with missing values on both specific and generic skills were listwise excluded from the sample (total of 12.6\%).

\section{Educational signals}

First, apprenticeship at firm was measured with the question: "Did you have an internship or did you have a (paid) job at this (current) company/organization during your VET programme?". Respondents could answer with 'yes, an internship', 'yes, a (paid) job', 'yes, both', and 'no'. These response categories were then recoded into yes (1) and no (0). Missing values were recoded into a separate category/dummy.

Next, the type of track indicates whether graduates attended the school-based VET track (BOL) (0) or the work-based VET track (BBL) (1). We assume that the work-based track sends a more positive signal about graduates' labor productivity to employers than the school-based track. These two groups differ in some characteristics from each other. For example, men and older students ( 24 years and older) more often choose a workbased track (50.7\% and 39.8\%, respectively) rather than a school-based track (31.9\% and $14.4 \%)$. We take these differences between the groups into account by controlling for these and other characteristics in all our models (see Table 2).

Third, respondents had to indicate which of the following educational levels in VET they had completed: 'basic vocational training, level 2', vocational training, level 3, and 'middle management training, level 4'. We recoded these levels into dichotomous variables.

Finally, the respondents were asked to indicate their average graduation grade (approximately) for all subjects. The grades in the Dutch educational system range from 1 (very poor) to 10 (outstanding). Grades of 6 and higher are needed in order to pass the exams. Respondents were to choose between the following six response categories: '6.0, '6.5, '7.0' '7.5, ' 8.0 ', and ' 8.5 or higher'. The item was recoded into an interval variable (ranging from 6.0 to 8.5$)$. Cases with missing values $(0.8 \%)$ on this measurement were deleted. In sum, a total of $13.3 \%$ respondents with missing values on (one of) the independent 
variables were excluded. Our final analytical sample size consisted out of 6014 graduated school-leavers.

\section{Control variables}

We included educational sector, gender, age, ethnic background, and parental educational background as control variables, as these factors could be common causes of both skills and signals, and graduates' labor market outcomes. Educational sectors within Dutch VET education can be categorized into five broader subject fields (Ministry of Education Culture and Science 2016, p. 12; OECD 2016, p. 28). As such, we measured these broader categories by means of five dummies: economics, technology, agriculture, health care, and social work/welfare. Gender was coded (0) for men and (1) for women. Age was measured in years. Ethnic background indicated whether at least one of the parents was born in a western or non-western foreign country, which is in line with the definition used by Statistics Netherlands (2018). The response categories were recoded into four dummies: 'native Dutch,' 'western migration background,' 'non-western migration background', and 'missing values ethnic background'. Parental educational background was measured through parents' educational level of which the highest educational level was coded as such. Five dummies were created: 'primary education', 'lower secondary education', 'upper secondary general education,' 'upper secondary vocational education, and 'tertiary education'. Missing information from one or both parents was grouped in a separate dummy. The descriptive statistics for all variables can be found in Table 1.

\section{Methods}

To test hypotheses 1 to 5 , we conducted binomial logistic regression analysis, because all labor market outcomes are dichotomous. To provide a better overview of the results, we only present the full models in Table 2 , as the results did not substantially differ from the models including only the skills or signal variables and controls (models available upon request).

Additional statistical methods were required for empirically testing hypotheses 6 and 7. For these hypotheses, we needed methods that were able to statistically test whether or not significant differences are found between the same predictor and the three labor market outcomes. We therefore conducted a generalized structural equation modeling (GSEM) analysis for which the average marginal effects were obtained, followed by a post-estimation Wald test (see Table 3). The GSEM analysis enabled us to run the models on the three outcome variables simultaneously, and provided the exact same outcomes (B-coefficients and average marginal effects) as the binomial logistic regression models presented in Table 2. After that, post-estimation Wald tests were conducted on the average marginal effects to investigate whether one predictor variable was significantly differently associated with one labor market outcome compared to the other, by imposing equality constraints on the coefficients and then evaluating the change in model fit (based on the $\mathrm{Chi}^{2}$ statistic), combined with its significance. Positive, significant values 
Table 1 Descriptive statistics of all variables $(N=6014)$. Source: VET survey 2015 collected by ROA of Maastricht University

\begin{tabular}{|c|c|c|c|c|}
\hline & Min. & Max. & Mean & Std. dev. \\
\hline \multicolumn{5}{|l|}{ Dependent variables } \\
\hline Immediate job entry & 0 & 1 & 0.81 & \\
\hline Horizontal match & 0 & 1 & 0.71 & \\
\hline Vertical match & 0 & 1 & 0.74 & \\
\hline Job security & 0 & 1 & 0.37 & \\
\hline \multicolumn{5}{|l|}{ Self-rated skills } \\
\hline Self-rated specific skills & 1 & 5 & 3.87 & 0.63 \\
\hline Self-rated generic skills & 1 & 5 & 3.79 & 0.66 \\
\hline \multicolumn{5}{|l|}{ Educational signals } \\
\hline \multicolumn{5}{|l|}{ Apprenticeship at firm (no= ref.) } \\
\hline Yes & 0 & 1 & 0.49 & \\
\hline Missing & 0 & 1 & 0.00 & \\
\hline \multicolumn{5}{|l|}{ VET track (school-based = ref.) } \\
\hline Work-based VET track & 0 & 1 & 0.25 & \\
\hline \multicolumn{5}{|l|}{ Educational VET level (level $2=$ ref.) } \\
\hline VET level 3 & 0 & 1 & 0.30 & \\
\hline VET level 4 & 0 & 1 & 0.56 & \\
\hline Average graduation grade & 6 & 8.5 & 7.32 & 0.54 \\
\hline \multicolumn{5}{|l|}{ Controls } \\
\hline \multicolumn{5}{|l|}{ Educational sector } \\
\hline Economics (=ref.) & 0 & 1 & 0.28 & \\
\hline Agriculture & 0 & 1 & 0.06 & \\
\hline Technology & 0 & 1 & 0.23 & \\
\hline Social work/welfare & 0 & 1 & 0.14 & \\
\hline Health care & 0 & 1 & 0.29 & \\
\hline Female & 0 & 1 & 0.63 & \\
\hline Age & 18 & 27 & 22.05 & 1.92 \\
\hline \multicolumn{5}{|l|}{ Ethnic background } \\
\hline Native Dutch (= ref.) & 0 & 1 & 0.32 & \\
\hline Western migration background & 0 & 1 & 0.20 & \\
\hline Non-western migration background & 0 & 1 & 0.24 & \\
\hline Missing & 0 & 1 & 0.08 & \\
\hline \multicolumn{5}{|l|}{ Parental educational background } \\
\hline Primary education (= ref.) & 0 & 1 & 0.02 & \\
\hline Lower secondary education & 0 & 1 & 0.18 & \\
\hline Upper secondary gen. education & 0 & 1 & 0.06 & \\
\hline Upper secondary VET education & 0 & 1 & 0.39 & \\
\hline Tertiary education & 0 & 1 & 0.28 & \\
\hline Missing & 0 & 1 & 0.07 & \\
\hline
\end{tabular}

then exemplified that the average marginal effects differed significantly from each other. To determine whether the predictor variable had a stronger relation with either the one or the other labor market outcome, we compared the effect sizes of the average marginal 
effects from the binomial logistic regression models, as they are identical to the average marginal effects from the GSEM models.

\section{Results}

\section{Self-rated specific versus generic skills \& labor market integration}

Table 2 shows the parameter estimates and average marginal effects of the binomial logistic regression models. Our results show that, among VET graduates, having more self-rated specific skills is indeed more positively related to immediate job entry (H1a), job matching (H1b) and job security (H1c) compared to having more self-rated generic skills. These findings are in accordance with hypothesis 1 . Although we found different relationships between both types of self-rated skills and our labor market outcomes, a significantly positive association is found between self-rated specific and generic skills when conducting linear regression models including all variables at once and the labor outcomes in turns. This re-confirms the fact that even though both self-rated skills are positively and robustly correlated with one another, they do have different associations with the labor market outcomes under investigation.

Unexpectedly, graduates with higher levels of self-rated generic skills are negatively associated with horizontal job matching. Perhaps this finding indicates that generic skills are indeed a means of diversion for job seekers, as these skills can be used well outside their own occupational domain, resulting in more flexibility on the labor market and therefore also increased chances of job mismatching (Borghans and De Grip 1999). Another alternative explanation is that horizontal job mismatches occur more often in less occupation-specific jobs, and as a result, graduates may have developed more (selfrated) generic skills in these jobs.

Regarding our control variables, we found that healthcare graduates have higher labor market chances on all outcomes than their counterparts from economics. Moreover, graduates from social work/welfare have overall lower labor market chances than the economics group. Next, we observed that women are less likely than men to experience immediate entry or a secure job. Regarding age, we found that older graduates have lower chances of immediate entry, but higher chances of a vertical matching job. Lastly, graduates with a non-western migration background are, on average, less likely to experience immediate job entry, horizontal matching, vertical matching (although marginally) and job security compared to graduates with a native Dutch background. In addition, graduates with a western migration background only have lower chances to find a vertical matching job than native Dutch graduates.

\section{Educational signals and labor market integration}

Table 2 also shows the results regarding the impact of educational signals on labor market integration (see hypotheses 2, 3, 4, and 5). Overall, these findings indicate that graduates' higher level of self-rated specific skills and (most of) the educational signals under investigation are independently of one another positively related to youth labor market integration.

First, having a pre-existing relationship with a firm (through an internship or a prior job during the VET programme) increases graduates' chances on all four labor market outcomes. The same is largely true for graduates who finished a work-based track, but 


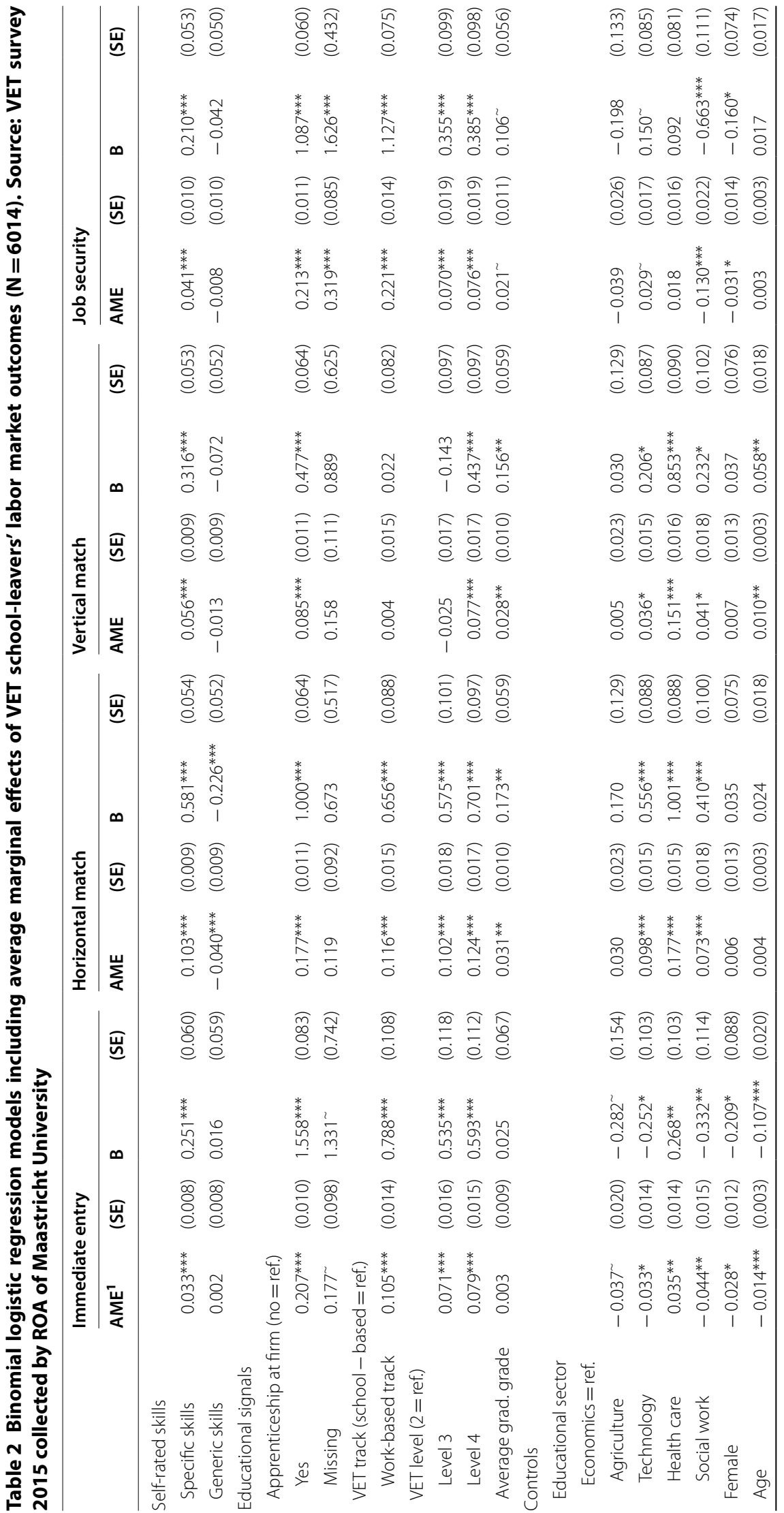




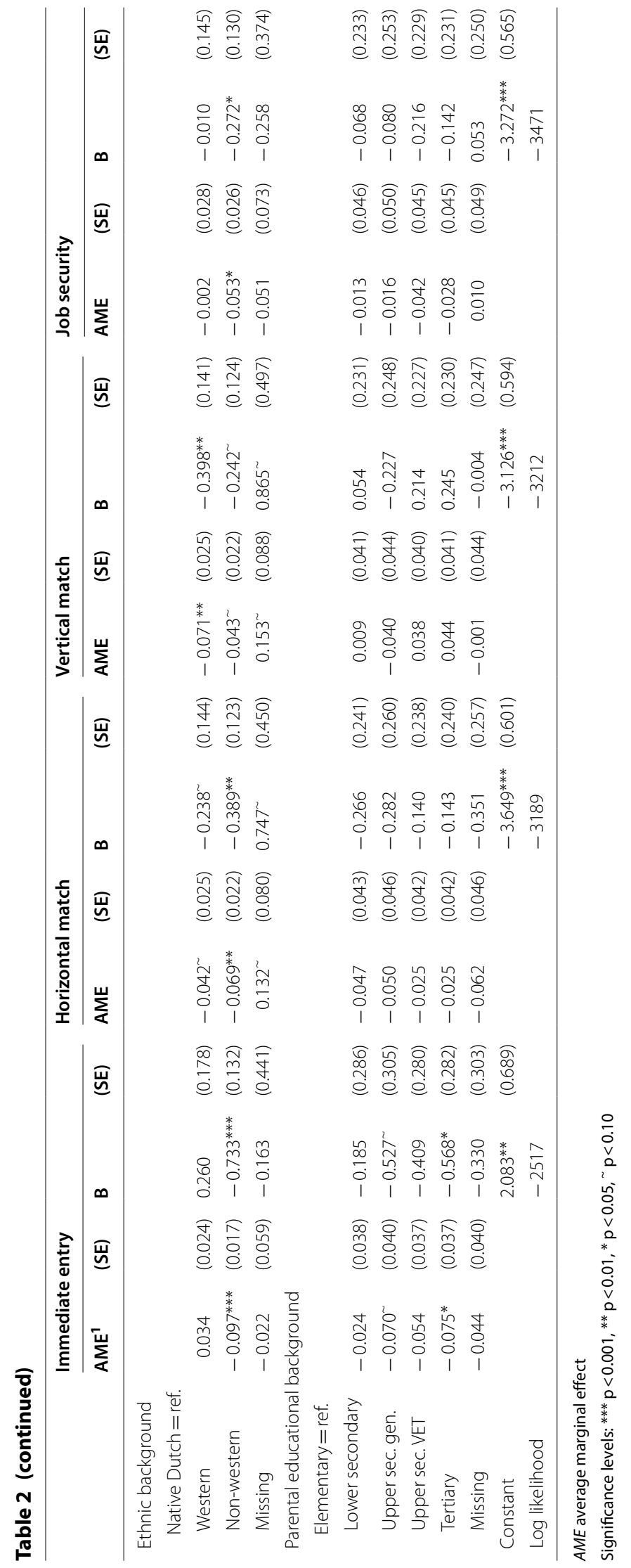


with the exception of vertical matching. For the majority of the outcomes, these results thus indicate that a work-based track sends a strong positive signal to employers, independently of graduates' pre-existing relationship with the firm. Support is found for hypotheses 2 and 3, with the exception of H3c (vertical matching). This indicates that network mechanisms and signals of on-the-job experience (i.e. immediate productivity) are important signals for VET graduates to send to employers.

Second, graduates from VET level 3 and level 4 are both more likely to experience immediate job entry, horizontal matching and job security compared to graduates from level 2. Interestingly, only in the case of vertical matching no significant differences are found between graduates from VET level 3 and level 2. Moreover, graduates from VET level 4 are more likely to experience a vertical job match compared to those from both level $3(\mathrm{AME}=0.103)$ and level $2(\mathrm{AME}=$ n.s. $)$. To conclude, it seems that those graduates that have attained the highest level within VET have significantly more chances to find a job that matches their educational level within VET (i.e. vertical matching) compared to those from lower VET levels. This can possibly be explained by the monopolizing position of VET level 4 occupations among VET graduates. Those with higher educational levels (within VET) are able to cascade down on the VET occupational ladder, whereas job seekers with lower attained VET levels are not eligible for occupations that require a level 4 degree. Their access is restricted, because they do not hold the required licensure or certificate. This 'closure by degree argument' (Bol and Weeden 2014) for increased chances of vertical matching among VET level 4 graduates seems plausible, as these programmes prepare students with additional specializations and hold managerial, coordinating responsibilities.

In addition to this, having a pre-existing relationship with the firm, thus network mechanisms, seem to increase chances of finding a job that matches graduates' educational level. Moreover, educational sectors, especially healthcare, are strongly related with chances of vertical job matching. This can also be explained by processes of credentialing (Bills 2003) and occupational regulations, which restrict access to holders of a particular certificate or licenses (Bol and Weeden 2014).

Lastly, with respect to average graduation grade, results show that higher average graduation grades among graduates are indeed more positively related to job matching and job security, supporting most of hypothesis 5 . As this does not hold true for immediate entry, we cannot confirm H5a. A possible explanation for the latter may be that signals of on-the-job experience (work-based track) and network mechanisms (internship at firm) may be more important for increasing graduates' chances of immediate job entry.

\section{Differences between labor market outcomes}

The GSEM analysis combined with the post-estimation Wald Test (see Table 3) provides information to test hypotheses 6 and 7. Hypothesis 6 states that the impact of educational signals is more positively related to immediate job entry compared to horizontal matching (H6a), vertical matching (H6b) and job security (H6c).

First, regarding apprenticeship at the firm, Table 3 shows that its impact is different between job entry and both horizontal $\left(\mathrm{Chi}^{2}=3.94\right)$ and vertical matching $\left(\mathrm{Chi}^{2}=64.19\right)$. Turning to the average marginal effects in Table 2, the positive apprenticeship impact is stronger for job entry than for horizontal and vertical matching, which is in line with our 
Table 3 Post-estimation Wald tests with Chi square test statistics $\left(X^{2}\right)$ : Comparing labor market outcomes $(\mathrm{N}=6014)$. Source: VET survey 2015 collected by ROA of Maastricht University

\begin{tabular}{|c|c|c|c|c|c|c|}
\hline & \multicolumn{6}{|l|}{ Signals } \\
\hline & $\begin{array}{l}\text { Self-rated } \\
\text { specific } \\
\text { skills }\end{array}$ & Apprenticeship & $\begin{array}{l}\text { Work-based } \\
\text { track }\end{array}$ & VET level 3 & VET level 4 & $\begin{array}{l}\text { Average } \\
\text { grad. } \\
\text { grade }\end{array}$ \\
\hline & $x^{2}$ & $x^{2}$ & $x^{2}$ & $x^{2}$ & $x^{2}$ & $x^{2}$ \\
\hline \multicolumn{7}{|l|}{ Job entry } \\
\hline Horizontal match & $32.73^{* * *}$ & $3.94^{*}$ & 0.31 & 1.73 & $4.09^{*}$ & $4.01^{*}$ \\
\hline Vertical match & $3.44^{\sim}$ & $64.19^{* * *}$ & $24.54^{* * *}$ & $17.14^{* * *}$ & 0.00 & $3.16^{\sim}$ \\
\hline Job security & 0.37 & 0.21 & $34.99 * * *$ & 0.00 & 0.02 & 1.54 \\
\hline
\end{tabular}

expectations. No significant differences are found between job entry and job security in Table $3\left(\mathrm{Chi}^{2}=\right.$ n.s.). This finding indicates that network mechanisms and/or (on-the-) job experience are as important for increasing chances of immediate entry as it is for increasing chances of permanent employment in the first 18 months of graduates' integration process. In order to explain the remaining findings as clearly as possible, we will discuss these more straightforwardly.

Next, the impact of type of VET track differs significantly between job entry and both vertical job matching $\left(\mathrm{Chi}^{2}=24.54\right)$ and job security $\left(\mathrm{Chi}^{2}=34.99\right)$. Graduates' type of VET track more strongly increases chances of job entry than vertical matching. Unexpectedly, type of VET track more strongly increases graduates' chances of job security rather than job entry. This finding indicates that having accumulated more (on-the-)job experience strongly increases graduates' chances of having a permanent employment contract within 18 months after school-leaving.

Third, and in line with our expectations, the impact of VET level 3 is significantly larger for immediate job entry than for vertical job matching. On the contrary, we found that signals of completing VET level 4 and average graduation grade more strongly increase chances of horizontal matching than job entry, which does not corroborate with hypothesis 6. Possibly, signals of overall trainability are more important for finding a job within one's field, whereas for immediate entry apprenticeship training and a work-based track seem most important.

Altogether, these findings partly confirm hypothesis 6: only the impact of graduates' apprenticeship is stronger for job entry than for horizontal and vertical matching. In addition, the impact of completing a work-based track and that of VET level 3 have a stronger positive impact on job entry than vertical matching. Unexpectedly, the impact of the other educational signals either (i) do not differ between job entry and the other labor outcomes (see Table 3) or (ii) do differ significantly, but in the opposite direction than predicted (see Table 2, i.e. the impact of VET level 4 and average graduation grade is stronger for horizontal matching, and the impact of the work-based track is stronger for job security).

Lastly, hypothesis 7 states that graduates' self-rated specific skills are more positively related to horizontal matching (H7a), vertical matching (H7b) and job security (H7c) than to immediate job entry. Results in Table 3 show that graduates' self-rated specific 
skills do significantly differ in relation to immediate entry and horizontal matching, and is indeed stronger for horizontal matching than immediate entry. However, the association between self-rated specific skills and the other labor market outcomes under investigation do not significantly differ from one another. As a result, we reject H7b and H7c: self-rated specific skills are as important for immediately entering a job as these are for allocating graduates to a vertical matching job and a secure job.

\section{Discussion}

This paper first of all aimed to answer the question: To what extent are self-rated specific and generic skills and different types of educational signals positively related to the labor market integration process of graduated school-leavers from vocational education in the Netherlands? With respect to the first part of this research question, a careful interpretation we can provide is that self-rated specific skills-acquired either in education or onthe-job-seem more positively related to favorable labor market outcomes than generic skills in the first 18 months of graduates' integration process. These findings do not seem to corroborate with human capital's general assumption that regardless of the type of skills, the more skills, the better the labor market returns, as we have found that the different types of self-rated skills are actually differently associated with labor market integration. This suggests that the extent to which the type of self-rated skills positively relate to labor market integration might depend on the educational and labor market context, which is in line with what most previous (cross-national) studies have theorized as well (Andersen and Van de Werfhorst 2010; Di Stasio and Van de Werfhorst 2016; Iannelli and Raffe 2007; Raffe 2008; Wolbers 2007). Accordingly, we encourage future research to place human capital theory within the educational and labor market context in order to further disentangle the impact of various types of (self-rated) skills on youth labor market integration.

However, it is important to not turn a blind eye for reversed causality in that a favorable labor market outcome might lead to a higher self-assessment of job-specific skills compared to generic skills (although there is a positive and robust relationship between both types of skills). Taking this causality issue into account, the answer would be to stay keen in ensuring that students enrolled in VET (also) develop generic skills. Besides the likely situation that in some occupations generic skills are in part also specific skills, generic skills are especially important with regard to VET students' opportunities to access higher levels within VET or to access tertiary, non-academic education. Given that the VET system not only prepares its students for the labor market, but also serves as a(n indirect) pathway to tertiary non-academic education, in particular for those from lower social origins, a relevant question remains to what extent the emphasis on specific skills within VET increases educational inequality by dampening further educational opportunities (see Bol and Van de Werfhorst 2013; Pfeffer 2015).

With regard of the second part of the first research question, we used a more extensive concept of educational signals, which enabled us to provide a more detailed picture of the impact of different types of graduates' signals on their labor market outcomes. Having had an apprenticeship (or a prior job) at the firm and completing a work-based VET track increases their chances of immediate entry, horizontal matching and job security. These two indicators signal more on-the-job experience and thus a higher productivity 
to employers. More importantly, the positive impact of apprenticeship at the firm more so indicates that network mechanisms and screening mechanisms are at work: employers are able to pre-screen the student and assess their trainability indicating whether they are fit for the job (Di Stasio and Van de Werfhorst 2016). This seems to provide vocational graduates a foot in the door for staying at the firm (see also Protsch 2017).

Next, the observed positive impact of higher VET levels compared to the lowest VET level on youth's labor market integration indicates that, even within VET, a lower educational attainment or degree will place graduates in a lower rank in the job queue (Gesthuizen et al. 2010; Spence 1973). Interestingly, it seems that graduates that have attained the highest level within VET (level 4) have more chances of finding a job that matches their educational level within VET (i.e. vertical matching) compared to graduates from lower VET levels. This finding indicates that 'closure by degrees' (Bol and Weeden 2014) might be at work, which can explain the monopolizing position of VET level 4 occupations among VET graduates. In short, graduates with higher educational levels within VET are able to cascade down on the VET occupational ladder, whereas for graduates with lower attained VET levels access to occupations that require a level 4 degree, and with that certain certificates or licensure, is restricted.

Lastly, average graduation grade only increases graduates' chances of horizontal and vertical matching, which might indicate that grades may play a decisive role when job seekers with similar qualifications (i.e. equal field or level of education) apply for the same job. Grades did however not increase chances of immediate entry and job security, which is in line with previous empirical findings regarding employment chances in the Netherlands (e.g. Di Stasio and Van de Werfhorst 2016; Iannelli and Raffe 2007).

The second research question we aimed to answer reads: To what extent does the role of self-rated specific skills and educational signals vary between different labor market outcomes among graduated school-leavers from vocational education in the Netherlands? Some of our results indicate that signals are indeed more impactful for immediate entry than the other labor market outcomes under investigation. However, and in contrast with our theoretical arguments, opposite or no results were also found. We shortly point out the most interesting findings. First, network mechanisms (i.e. apprenticeship training) and on-the-job experience (i.e. apprenticeship training and work-based VET track) are more important for experiencing job entry compared to experiencing horizontal and vertical matching. Second, one unexpected but explainable conclusion is that these mechanisms are as important for increasing graduates' chances of permanent employment as they are for chances of immediate entry. In the case of graduates' type of VET track, this signal seemed even more important for increasing graduates' chances of permanent employment rather than immediate entry. Lastly, one's educational level within VET and one's average graduation grade seem more important for increasing graduates' chances of finding a job within one's field (i.e. horizontal matching) rather than for immediate entry.

An important reason why we found mixed results and why it is difficult to pinpoint to what extent alternative explanations are at work is due to the fact that immediate job entry relates to graduates' period directly after graduation, whereas the other outcomes may relate to their situation 18 months after graduation. Although our results did not provide entirely unambiguous answers-we think it is important for future research to 
explore this further, as it provides insights into which signal is most impactful for which labor market outcome. In order to examine in greater detail how the labor market integration process works from a more dynamic perspective, the first step is to make sure that the labor market outcomes cover the same period, as it is quite possible that the impact of certain types of skills and signals change over the course of time. For instance, previous research found that the impact of skills on earnings can change over the life course (see Forster et al. 2016; Hanushek et al. 2017).

In addition to our contributions, we would like to point towards four improvements that can be made regarding our data and measures. First, and related to our second research question, not all indicators of labor market integration analyzed in this paper pertain to the first job. Immediate job entry does, but job matching and job security have been measured at the time of the current job, one and a half year after graduation. For the period between the first and current job, it is unknown whether graduates shifted between employers or changed jobs within the same employers. Future research could fill in this gap by investigating this type of information, either in prospect, retrospect or by means of a longitudinal design.

Second, our measurement of both specific and generic skills was based on selfassessed ratings of graduates' current level of skills, measured one and a half years after graduation. The skills pertaining to the current situation can be partly based on the skills acquired on the job (i.e. obtained after and outside vocational education). Causality can therefore for some part be reverse and needs to be interpreted with caution. We tried to interpret our findings as carefully as possible, by interpreting these skills as being acquired both in education and in the labor market, and by steering away from causal interpretations of the findings. To our knowledge, we were at least able to include a measurement of self-rated specific skills (on the micro-level), by which we provide a, perhaps not perfect, step forward, and by which we aim to provide new insights on the relationship between self-rated specific skills and youth labor market integration. In future data collections, a further step would be to measure both kinds of skills exclusively related to the educational programme in vocational education.

Third, even though generic skills are commonly conceptualized as having oral, written or numeracy skills in the literature (Meng 2006; Van der Velden 2011) and widely tested as such by means of IALS and PIAAC, in some occupations these skills can actually for some part be defined as specific skills. Having high levels of calculating skills might for instance be a specific requirement in medical occupations where doses of medication have to be calculated. This is one of the reasons why job-specific skills are difficult to quantify. Future research can advance by performing expert interviews within occupations to determine which skills are deemed important, and to what extent they are considered generic or specific.

Fourth and last, similar to previous studies we examined VET graduates' overall average graduation grade (see Di Stasio and Van de Werfhorst 2016; Protsch 2017; Protsch and Solga 2015). In line within the framework of queuing and signaling, higher average graduation grades indicate higher levels of trainability and perseverance to employers (Bills 2003; Spence 1973; Weiss 1995). Although the type of school grades are not further specified by these theoretical frameworks, it might be interesting for future research to 
make a distinction between specific and generic grades as it might provide more detailed insights into the impact of both types of grades on youth labor market integration.

\section{Conclusion}

Our first contribution to the field was to simultaneously investigate the role of both self-evaluated skills and educational signals in the first 18 months of Dutch VET graduates' labor market integration process. With this, our aim was to get more insight in the extent to which different types of self-rated skills and educational signals are beneficial to youth's labor market integration.

First of all, as graduates evaluated their current level of skills after 18 months after school-leaving, it is possible that we did not solely capture their self-rated skills acquired in education, but skills that may have further accumulated on the job and over that time period. For the Netherlands, a cautious interpretation of our findings is therefore that only graduates' self-rated specific skills-acquired either in education or on-the-jobare positively related to the investigated labor market outcomes, and that generic skills in the first 18 months of their integration process do not (or even negatively) affect labor market success. However, as reversed causality might play a role in our skill measurements, the role of generic skills in vocational education should not be underestimated. In fact, it should again be pointed out that generic skills are important, especially regarding VET students' opportunities to access higher levels within VET or tertiary education. Furthermore, our findings indicate that graduates' level of self-rated skills and (most of) the educational signals under investigation are independently of one another positively related to youth labor market integration.

Our second contribution was the use of a more extensive concept of educational signals by investigating different types of signals and theorizing how each signal can affect youth's labor market integration. Overall, the most important conclusion we draw from our empirical results is that different types of signals can increase graduates' labor market chances for different underlying reasons. Thus, the type of signals does matter for labor market integration (see also Di Stasio and Van de Werfhorst 2016; Protsch and Solga 2015). We therefore suggest future research to focus on a more extensive concept of educational signals by examining in more detail how different educational signals relate to youth labor market integration.

The third and last contribution of this paper was to a priori theorize and empirically test whether and why (self-rated) skills and signals have a stronger impact on one labor market outcome compared to the other. To our knowledge, this question has remained under-investigated in previous research on school-to-work transitions. We found that the impact of one type of signal (or skill) varies in strength between different labor market outcomes. One unambiguous conclusion we draw from our findings is that apprenticeship training and a work-based track (i.e. network mechanisms and on-thejob experience) are more important for graduates' chances to experience immediate job entry and permanent employment compared to horizontal and vertical matching. As we made some first steps in investigating this question, we encourage future research to further explore this, as it may provide more nuanced insights into which signal is most impactful for which labor market outcome. 


\section{Abbreviations}

AME: average marginal effect; GSEM: Generalized Structural Equation Model; IALS: International Adult Literacy Survey; ISCED: International Standard Classification of Education; PIAAC: Programme for the International Assessment of Adult Competencies; ROA: Research Centre for Education and the Labor Market; VET: Vocational Education and Training.

\section{Authors' contributions}

AM wrote the manuscript under supervision of $L B, M G$, and MW. All authors read and approved the final manuscript.

\section{Acknowledgements}

Earlier versions of this paper have been presented at the Day of Sociology 2017, ICS Spring Forum Day, RC28 Summer Meeting 2017, and TIY 2017. The authors would like to thank the participants as well as the two anonymous reviewers for their helpful comments and suggestions.

\section{Competing interests}

The authors declare that they have no competing interests.

\section{Availability of data and materials}

The 2015 VET monitor was collected by the Research Centre for Education and the Labor Market (ROA), research institute of Maastricht University School of Business and Economics in the Netherlands. The secondary data was publicly available on the certified website of Data Archiving and Networked Services, also known as DANS (https://doi.org/10.17026/ dans-za4-nyp5).

\section{Funding}

Funding for the project was provided by Instituut Gak (Grant Number 2015 - 680).

\section{Publisher's Note}

Springer Nature remains neutral with regard to jurisdictional claims in published maps and institutional affiliations.

\section{Received: 24 October 2018 Accepted: 13 March 2019}

Published online: 18 March 2019

\section{References}

Andersen R, Van de Werfhorst HG (2010) Education and occupational status in 14 countries: the role of educational institutions and labour market coordination. Br I Sociol 61(2):336-355

Arrow KJ (1973) Higher education as a filter. J Public Econ 2(3):193-216

Arum R, Shavit Y (1995) Secondary vocational education and the transition from school to work. Sociol Educ 68(3):187-204

Barone C, Van de Werfhorst HG (2011) Education, cognitive skills and earnings in comparative perspective. Int Sociol 26(4):483-502

Becker GS (1964) Human capital: a theoretical and empirical analysis, with special reference to education. University of Chicago Press, Chicago

Bills DB (2003) Credentials, signals, and screens. Explaining the relationship between schooling and job assignment. Rev Educ Res 73(4):441-469

Bol T, Weeden KA (2014) Occupational closure and wage inequality in Germandy and the United Kingdom. Eur Sociol Rev 31(3):345-369

Bol T, Van de Werfhorst HG (2011) Signals and closure by degrees: the education effect across 15 European countries. Res Soc Stratif Mobil 29(1):119-132

Bol T, Van de Werfhorst HG (2013) Educational systems and the trade-off between labor market allocation and equality of educational opportunity. Comparat Educ Rev 57(2):285-308

Borghans L, De Grip A (1999) Skills and low pay: upgrading or overeducation? No. 005. Research Centre for Education and the Labour Market, Maastricht

Coenen J, Heijke H, Meng C (2015) The labour market position of narrow versus broad vocational education programmes. Empir Res Vocat Educ Train 7(1):1-9

De Grip A, Wolbers MHJ (2006) Cross-national differences in job quality among low-skilled young workers in Europe. Int Manpow 27(5):420-433

Di Stasio V, Van de Werfhorst HG (2016) Why does education matter to employers in different institutional contexts? A vignette study in England and the Netherlands. Soc Forces 95(1):77-106

Dieckhoff M (2008) Skills and occupational attainment: a comparative study of Germany, Denmark and the UK. Work Employ Soc 22(1):89-108

Forster AG, Bol T, Van de Werfhorst HG (2016) Vocational education and employment over the life cycle. Sociol Sci 3:473-494

Gesthuizen M, Solga H, Künster R (2010) Context matters: economic marginalization of low-educated workers in crossnational perspective. Eur Sociol Rev 27(2):264-280

Hannan D, Raffe D, Smyth E (1997) Cross-national research on school to work transitions: an analytic framework. In: Wequin P, Breen R, Planas J (eds) Youth transitions in Europe: theory and evidence. CEREQ, Marseilles, pp 409-442

Hanushek EA, Woessmann L, Zhang L (2017) General education, vocational education, and labor market outcomes over the lifecycle. J Hum Resour 52(1):48-87 
Heijke H, Meng C, Ris C (2003) Fitting to the job: the role of generic and vocational competencies in adjustment and performance. Labour Econ 10(2):215-229

Heisig JP, Solga H (2015) Secondary education systems and the general skills of less and intermediate-educated adults: a comparison of 18 countries. Sociol Educ 88(3):202-225

lannelli C, Raffe D (2007) Vocational upper-secondary education and the transition from school. Eur Sociol Rev 23(1):49-63

Kerckhoff AC (2001) Education and social stratification processes in comparative perspective. Sociol Educ Work 74:3-18

Lazear EP (2009) Firm-specific human capital: a skill-weights approach. J Polit Econ 117(5):914-940

Levels M, Van der Velden R, Di Stasio V (2014) From school to fitting work: how education-to-job matching of European school leavers is related to educational system characteristics. Acta Sociol 57(4):341-361

Meng C (2006) Discipline-specific or academic? Acquisition, role and value of higher education competencies. PhD thesis, University of Maastricht: Research Centre for Education and the Labor Market, the Netherlands

Ministry of Education Culture and Science (2016) Key figures education. The Hague: Rijksoverheid. https://www.ocwin cijfers.nl/documenten/publicaties/2016/05/31/key-figures-education. Accessed 5 Mar 2019

Noelke C (2015) Employment protection legislation and the youth labor market. Eur Sociol Rev 32(4):471-485

OECD (2016) Netherlands 2016: foundations for the future, reviews of national policies for education. OECD Publishing, Paris

Pfeffer FT (2015) Equality and quality in education. A comparative study of 19 countries. Soc Sci Res 51:350-368

Protsch P (2017) Getting a foot in the door: how organisational characteristics shape recruitment decisions in the dual apprenticeship system. J Educ Work 30(6):585-598

Protsch P, Solga H (2015) How employers use signals of cognitive and non-cognitive skills at labor market entry: insights from field experiments. Eur Sociol Rev 31(5):521-532

Raffe D (2008) The concept of transition system. J Educ Work 21(4):277-296

Rosenbaum JE, Kariya T, Settersten R, Maier T (1990) Market and network theories of the transition from high school to work: their application to industrialized societies. Ann Rev Sociol 16(1):263-299

Scherer S (2005) Patterns of labor market entry-long wait or career instability? An empirical comparison of Italy, Great Britain and West Germany. Eur Sociol Rev 21(5):427-440

Shavit Y, Müller W (eds) (1998) From school to work. A comparative study of educational qualifications and occupational destinations. Clarendon Press, Oxford

Spence M (1973) Job market signaling. Quart J Econ 87(3):355-374

Statistics Netherlands (CBS) (2018) Migration Background. https://www.cbs.nl/en-gb/our-services/methods/definition $\mathrm{s}$ ?tab=m\#id=migration0-background

Thurow L (1976) Generating inequality. Basic Books, New York

Van de Werfhorst HG (2014) Changing societies and four tasks of schooling: challenges for strongly differentiated educational systems. Int Rev Educ 60(1):123-144

Van de Werfhorst HG, Mijs JJB (2010) Achievement inequality and the institutional structure of educational systems: a comparative perspective. Ann Rev Sociol 36:407-428

Van der Velden RKW (2011) Generiek of specifiek opleiden? Tijdschrift voor Arbeidsvraagstukken 27(3):382-397

Van der Velden RKW, Wolbers MHJ (2007) How much does education matter and why? The effects of education on socioeconomic outcomes among school-leavers in the Netherlands. Eur Sociol Rev 23(1):65-80

Vogtenhuber S (2014) The impact of within country heterogeneity in vocational specificity on initial job matches and job status. J Vocat Behav 85(3):374-384

Weiss A (1995) Human capital vs. signaling explanations of wages. J Econ Persp 9(4):133-154

Wolbers MHJ (2003) Job mismatches and their labor market effects among school-leavers in Europe. Eur Sociol Rev 19(3):249-266

Wolbers MHJ (2007) Patterns of labour market entry: a comparative perspective on school-to work transitions in 11 European countries. Acta Sociol 50(3):189-210 